\title{
PRODUÇÃO DE CORPOS CERÂMICOS A PARTIR DE ARGILA ADITIVADA COM POLPA DE PAPEL RECICLADO E COM EMBALAGEM ALUMINIZADA MOIIDA
}

\author{
Maria Claudia Nunes Kraemer e Ayrton Figueiredo Martins' \\ Departamento de Química - Centro de Ciências Naturais e Exatas \\ UFSM - Santa Maria, RS
}

\section{RESUMO}

Investigou-se a possibilidade de aproveitamento de polpa de papel reciclado (jornais velhos) e de embalagens aluminizadas (de leite longa vida) como aditivos para a argila vermelha na confecção de corpos cerâmicos maciços (tijolos). Além do aspecto tecnológico, são de grande interesse ambiental alternativas para o reaproveitamento de materiais descartados, integrantes do lixo comunitário.

A polpa de papel foi obtida a partir de simples desfibramento aquoso de jornais velhos, enquanto que, as embalagens de leite longa vida, por apresentarem camadas plástica e de alumínio estabilizado, sofreram redução de tamanho e subsequente cominuição em micro-moinho.

A argila para processo semi-úmido (com $5 \%$ a $10 \%$ de umidade) foi fornecida pela olaria anexa ao campus da UFSM. O processo de mistura da massa foi inteiramente manual, utilizando-se para tanto diversas proporções de argila/polpa de papel e de argila/embalagem aluminizada cominuída.

Os corpos cerâmicos foram moldados, também, manualmente (formas metálicas $30 \times 40 \times 60 \mathrm{~mm}$ ), obtendo-se uma massa compacta, aparentemente

1 Autor para correspondência 
homogênea. A seguir, os corpos de prova sofreram processos de pré-secagem, secagem e cozimento, segundo as normas NBR 7170 e NBR 8041.

Sob controle de qualidade externo (exame visual), as amostras demonstraram boas porosidade, homogeneidade e conformação, sendo então submetidas à testes de densidade e de resistência à compressão.

Os resultados obtidos permitem concluir que a adição de polpa de papel reciclado e de embalagem aluminizada triturada (em micro-moinho), em pequenas e determinadas proporções, à argila, não traz prejuízos à resistência mecânica de corpos cerâmicos, e pode ser vantajosa estruturalmente no aspecto de isolamento térmico e acústico em paredes internas residenciais.

\section{SUMMARY}

We investigated the possible use of recycled paper pulp (old newspapers) and aluminized packaging (long life milk) as additives to red clay in the prodution of solid ceramic bricks. Besides the technological aspect, there is an environmental interest to find alternative uses of discarded material which is part of the usual community waste.

The paper's pulp was obtained by simple defibriment of old newspapers in water, while the aluminized packaging, having a plastic layer and a layer of stable aluminum, underwent first a size reduction and then a grinding in a micro-grinder.

The clay for semiwet process (with $5 \%$ to $10 \%$ of humidity) was supplied by the brickworks near the UFSM campus. The process of mass mixture was totally manual with different proportions of clay/pulp of paper and clay/grounded aluminized packing used.

The ceramic test specimens were also manually molded (metalic mold with dimensions of $30 \times 40 \times 60 \mathrm{~mm}$ ), resulting a very homogeneous compact mass. Then they were submitted to pre-drying, drying and burning processes, according the NBR 7170 and NBR 8041 specifications.

The samples demonstrated good porousity, homogenity and conformation. They were then submitted to density and compression resistance tests. 
The results obtained allow us to conclude that the addition to clay of recycled paper pulp and ground aluminized packaging, in small proportions, doesn't result in any reduction of mechanical resistance in the ceramic specimens and it can be advantageous with respect to thermal and acoustic isolation.

\section{INTRODUÇÃO}

A indústria cerâmica engloba a arte, a ciência e a tecnologia de fabricar peças sólidas constituídas essencialmente por materiais inorgânicos nãometálicos, denominados materiais cerâmicos, após tratamento em temperaturas elevadas.

Os produtos cerâmicos podem ser obtidos a partir de argilas, de misturas de matérias inorgânicas naturais, óxidos inorgânicos puros, de carbetos, de nitretos, etc.; sendo classificados em cerâmica vermelha estrutural, cerâmica branca, refratários, vidros, cimentos, abrasivos, isolantes térmicos, titanatos, óxidos, cermetos e outros.

Na cerâmica vermelha empregam-se argilas plásticas, ricas em ferro $e$ outras impurezas naturais, para a confecção de produtos destinados à construção civil, objetos domésticos ou de adorno, sendo sua característica a coloração avermelhada. Dentre os diversos produtos fabricados com a cerâmica vermelha destacam-se os tijolos macicos, telhas, blocos de vedação, vasos, potes e outros. ${ }^{(1)}$

A argila é uma rocha finamente dividida, constituida essencialmente por argilo minerais, podendo conter outros minerais como quartzo, mica, calcita e dolomita. É plástica, quando pulverizada e molhada; rígida e dura, após secagem e queima. Os argilo minerais são os componentes básicos das argilas: silicatos hidratados de alumínio ou alumínio-magnesianos e podem conter estruturalmente outros elementos, tais como potássio, ferro, quartzo, sais solúveis, etc.. Devido aos argilo minerais, as argilas apresentam uma série de propriedades, como plasticidade, grau de viscosidade e resistência mecânica, das quais deriva o grande campo de aplicação tecnológica. ${ }^{(2)}$

As argilas também contém materiais orgânicos. Em pequenas proporções, a matéria orgânica aumenta a plasticidade das argilas, facilita a modelagem e 
aumenta a resistência à compressão do produto seco. A porosidade de um produto cerâmico deve-se, em parte, à queima da matéria orgânica. A presença de poros é uma propriedade desejável, pois é responsável, por exemplo, pela capacidade de isolamento térmico e acústico de um tijolo maciço. (3)

No entanto, teores excessivos de matéria orgânica podem causar trincas na secagem e na queima, devido à grande contração, com conseqüente redução da resistência mecânica.

Tendo em mente as características que a matéria orgânica confere ao produto cerâmico, investigou-se, então, a influência da adição à argila de polpa de papel reciclado e de embalagem aluminizada, nas características físicas de tijolos maciços. A embalagem contém, ademais, alumínio metálico, que, teoricamente, poderia aumentar a resistência mecânica de corpos cerâmicos, em virtude de eventuais reações com os argilo minerais à temperaturas elevadas.

\section{MATERIAIS E MÉTODOS}

\section{Seqüência adotada na produção de tijolos maciços em laboratório}

Coleta e armazenagem da argila: as amostras de argila, para processo semi-úmido (5 a $10 \%$ de umidade), foram coletadas diretamente da linha de produção da olaria e, convenientemente, conservadas em laboratório até posterior utilização (ambiente com temperaturas entre 15 e $20^{\circ} \mathrm{C}$, sem circulação de ar, ao abrigo da luz e com umidade constante). Nestas condições, desenvolvem-se bactérias aglomerantes que aumentam a plasticidade do material.

Preparação da matéria-prima: a polpa de papel foi preparada a partir de jornais velhos, primeiramente, submetidos a desfibramento em meio aquoso e, depois, à lavagem para retirar o excesso da tinta de impressão. As embalagens de leite longa vida foram, inicialmente, secas em estufa $\left(1 \mathrm{~h} / 60^{\circ} \mathrm{C}\right)$, sendo depois cortadas e moídas em micro-moinho, até se obter partículas de tamanho inferior a $1 \mathrm{~mm}$ de diâmetro. $\mathrm{O}$ processo de mistura e de homogeneização das amostras de argila aditivada foi inteiramente manual. Preparou-se, em triplicata, misturas de argila e polpa de papel nas seguintes proporções: 


\begin{tabular}{|c|c|c|}
\hline $\begin{array}{c}\text { Misturas } \\
(\% ; \mathrm{m} / \mathrm{m})\end{array}$ & Argila & Polpa de papel \\
\hline $\mathrm{n}^{\circ} 01$ & 100 & 0 \\
\hline $\mathrm{n}^{\circ} 02$ & 97,5 & 2,5 \\
\hline $\mathrm{n}^{\circ} 03$ & 95 & 5 \\
\hline $\mathrm{n}^{\circ} 04$ & 92,5 & 7,5 \\
\hline $\mathrm{n}^{\circ} 05$ & 90 & 10 \\
\hline
\end{tabular}

Da mesma forma, foram preparadas, em triplicata, misturas de argila e de embalagem aluminizada moída, nas seguintes proporções:

\begin{tabular}{|c|c|c|}
\hline $\begin{array}{c}\text { Misturas } \\
(\% ; \mathrm{m} / \mathrm{m})\end{array}$ & Argila & Polpa de papel \\
\hline $\mathrm{n}^{\circ} 01$ & 100 & 0 \\
\hline $\mathrm{n}^{\circ} 02$ & 99 & 1 \\
\hline $\mathrm{n}^{\circ} 03$ & 98 & 2 \\
\hline $\mathrm{n}^{\circ} 04$ & 97 & 3 \\
\hline $\mathrm{n}^{\circ} 05$ & 96 & 4 \\
\hline $\mathrm{n}^{\circ} 06$ & 95 & 5 \\
\hline $\mathrm{n}^{\circ} 07$ & 90 & 10 \\
\hline
\end{tabular}

Os corpos cerâmicos foram, então, prensados e moldados manualmente (formas de $30 \times 40 \times 60 \mathrm{~mm}$ ), obtendo-se uma massa compacta, homogênea e pouco porosa.

Secagem: escolheu-se a secagem natural, no ambiente do laboratório (ao abrigo da ação direta do sol, por periodo de 25 a 30 dias), pois sendo um processo lento, pouco agressivo à estrutura interna, leva a um corpo de prova homogêneo.

Queima: após o período de secagem, os corpos cerâmicos aditivados com polpa de papel, foram queimados em mufla, por 4 horas, em temperaturas que variaram entre $950^{\circ}$ e $1050^{\circ} \mathrm{C}$. Os corpos cerâmicos aditivados com embalagem aluminizada moída foram queimados nas mesmas condições, mas, por 5 horas, devido à presença de plástico. A taxa de aquecimento da mufla foi de $10^{\circ} \mathrm{C} / \mathrm{min}$ 
Controle de qualidade e testes mecânicos: terminado o processo de cozimento, as amostras foram submetidas a um controle de qualidade, onde foram desprezados e substituídos os corpos cerâmicos com rachaduras ou que estavam demasiadamente avermelhados, em razão de uma eventual má distribuição de calor no interior da mufla. As amostras aprovadas pelo controle de qualidade foram submetidas a testes de densidade e a testes de compressão (segundo as normas NBR 7170 e NBR 8041), junto ao Laboratório de Materiais de Construção Civil, do Departamento de Engenharia Civil da UFSM.

Normas ABNT: As normas existentes para tijolos cerâmicos maciços para alvenaria são a NBR 7170 e a NBR 8041. Alguns dos parâmetros da NBR 7170 e da NBR 8041 são: Características visuais - Os tijolos não devem apresentar defeitos sistemáticos tais como trincas, quebras, deformações ou desuniformidade da cor. Fabricação - O tijolo cerâmico maciço é fabricado com argila conformada por extrusão, queimado a temperaturas elevadas $\left(950^{\circ} \mathrm{C}\right.$ a $1400^{\circ} \mathrm{C}$ ). Características mecânicas - A principal é a resistência à compressão. A resistência à compressão, mínima, dos tijolos deve atender aos valores indicados na Tabela 1. Dimensões - O tijolo comum deve possuir a forma de um paralelepípedo, com as dimensões dadas na Tabela $2 .^{(4)}$

Tabela 1: Classificação de tijolos cerâmicos maciços em função da resistência à compressão, segundo normas da ABNT.

\begin{tabular}{cccc}
\hline \hline Categoria & $\begin{array}{c}\text { Resistência à Compressão } \\
\text { (MPa) }\end{array}$ & $\begin{array}{c}\text { Categori } \\
\text { a }\end{array}$ & $\begin{array}{c}\text { Resistência à compressão } \\
\text { (MPa) }\end{array}$ \\
\hline 10 & 1 & 60 & 6 \\
20 & 2 & 70 & 7 \\
30 & 3 & 80 & 8 \\
40 & 4 & 90 & 9 \\
50 & 5 & 100 & 10 ou mais
\end{tabular}

Tabela 2: Dimensões para tijolos cerâmicos maciços, segundo normas da ABNT.

\begin{tabular}{ccc}
\hline \hline Comprimento & Altura & Largura \\
\hline $19 \mathrm{~cm}$ & $9 \mathrm{~cm}$ & $5,7 \mathrm{~cm}$ \\
$19 \mathrm{~cm}$ & $9 \mathrm{~cm}$ & $9 \mathrm{~cm}$ \\
\end{tabular}




\section{RESULTADOS E DISCUSSÃO}

As amostras com até $7,5 \%$ de massa de polpa de papel reciclado (Fig.1) apresentaram densidades e resistências à compressão bastante satisfatórias, relativamente, o que as enquadram nas categorias de 100 a 60 , ou seja, de boas qualidades mecânicas (segundo a norma NBR 7170 , tijolos de categorias inferiores a 40 são inadequados).

No entanto, somente as amostras com até $3 \%$ de massa de embalagem aluminizada moída apresentaram densidades e resistência à compressão satisfatórias, enquadrando-se nas categorias de 100 a 60 (Fig.2). Atribui-se esta diminuição na resistência à presença de plástico nas embalagens que, durante a queima, pode ter causado uma dilatação interna excessiva no tijolo e, posteriormente, uma contração excessiva durante o arrefecimento (o que pode ser causa de micro-fraturas internas).

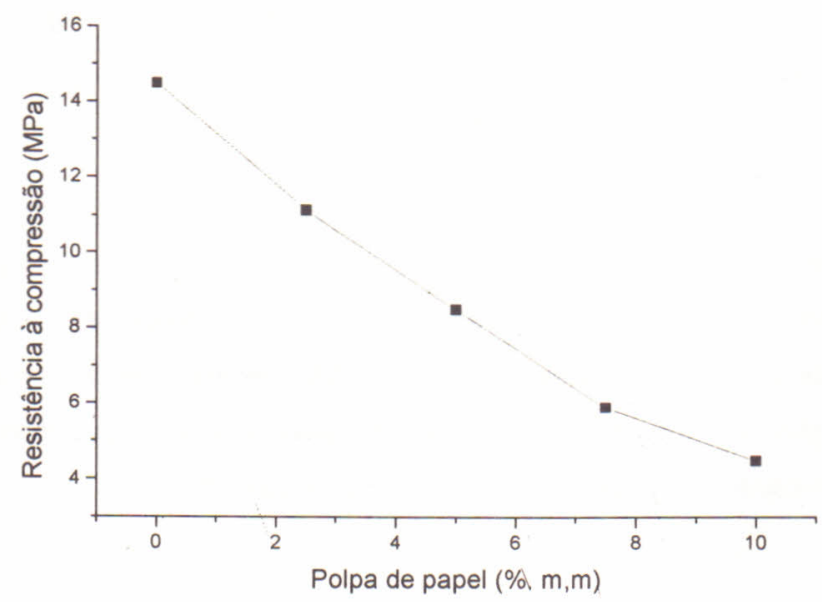

Figura 1. Relação obtida entre o teor de massa de polpa de papel nas amostras e a resistência mecânica à compressão

As amostra em geral mostraram uma boa porosidade e homogeneidade. As densidades ficaram entre 1,69 e 1,85 g/cm ${ }^{3}$, para as amostras 
aditivadas com polpa de papel, e, entre 1,45 e $1,84 \mathrm{~g} / \mathrm{cm}^{3}$, para as amostras com embalagem aluminizada moída.

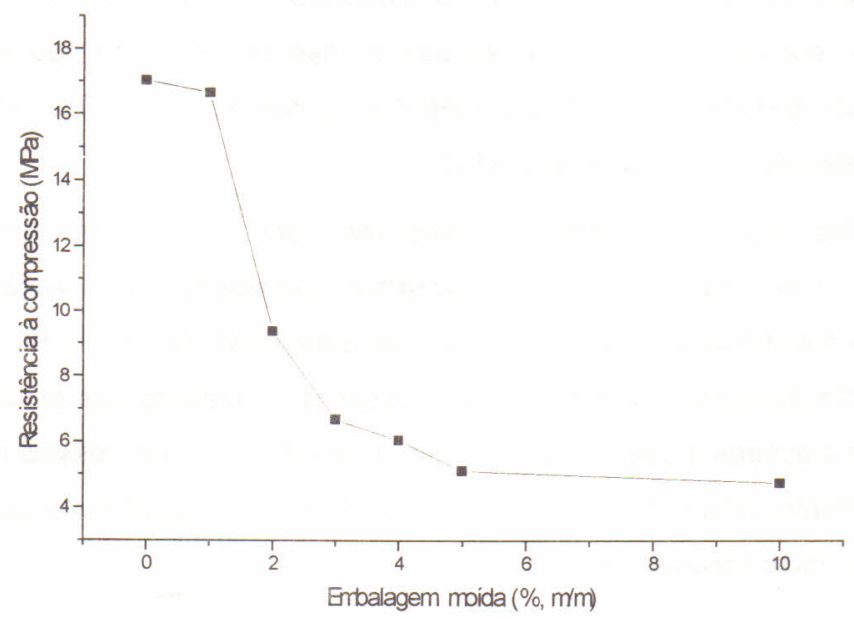

Figura 2. Relação obtida entre o teor de massa de embalagem de leite longa vida triturada nas amostras e a resistência mecânica à compressão.

\section{CONCLUSÃO}

Com base nestes resultados, pode-se concluir que, a adição de tais materiais descartados, objetos deste estudo, e integrantes do lixo comunitário, à argila da produção de tijolos maciços, constitui interessante alternativa tecnológica, de apreciável relevância ambiental. Não menos importante é o fato de que, com tal procedimento, é possível obter-se, relativamente, tijolos mais leves e com melhores capacidades de isolamento térmico e acústico.

\section{AGRADECIMENTOS}

Os autores agradecem ao CNPq, pelo auxílio financeiro prestado; à direção da olaria anexa ao campus UFSM, pelo fornecimento de argila; ao Prof. Francisco Ripolli Filho, pela orientação bibliográfica; e aos técnicos do Laboratório 
de Materiais de Construção Civil do Departamento de Engenharia Civil da UFSM, pelo auxílio nos testes mecânicos.

\section{BIBLIOGRAFIA CONSULTADA}

1- NORTON, Frederick H. - Introdução à Tecnologia Cerâmica. São Paulo, Ed. Universidade de São Paulo, 1973.

2- VAN VLACK, Lawrence H. - Propriedades dos Materiais Cerâmicos. São Paulo, Ed. Universidade de São Paulo, 1973.

3- GRIM, RALPH. E. - Clay Mineralogy, 2nd. ed., Macgraw Hill Book Company.

4- RIPOLLI FILHO, Francisco et al. - Curso Básico de Cerâmica Vermelha Estrutural, Polígrafo do Curso de Engenharia Civil da UFSM. 
? 